\title{
Comparative case study on website traffic generated by search engine optimisation and a pay-per-click campaign, versus marketing expenditure
}

\begin{tabular}{|c|c|}
\hline \multicolumn{2}{|c|}{$\begin{array}{l}\text { Authors: } \\
\text { Wouter T. Kritzinger }{ }^{1} \\
\text { Melius Weideman }^{1}\end{array}$} \\
\hline \multicolumn{2}{|c|}{$\begin{array}{l}\text { Affiliations: } \\
{ }^{1} \text { Website Attributes Research } \\
\text { Centre (WARC), Cape } \\
\text { Peninsula University of } \\
\text { Technology, South Africa }\end{array}$} \\
\hline \multicolumn{2}{|c|}{$\begin{array}{l}\text { Correspondence to: } \\
\text { Melius Weideman }\end{array}$} \\
\hline \multicolumn{2}{|c|}{$\begin{array}{l}\text { Email: } \\
\text { weidemanm@cput.ac.za }\end{array}$} \\
\hline \multicolumn{2}{|c|}{$\begin{array}{l}\text { Postal address: } \\
\text { PO Box 652, Cape Town 8000, } \\
\text { South Africa }\end{array}$} \\
\hline \multicolumn{2}{|c|}{$\begin{array}{l}\text { Dates: } \\
\text { Received: } 12 \text { Dec. } 2014 \\
\text { Accepted: } 17 \text { July } 2015 \\
\text { Published: } 22 \text { Sept. } 2015\end{array}$} \\
\hline \multicolumn{2}{|c|}{$\begin{array}{l}\text { How to cite this article: } \\
\text { Kritzinger, W.T. \& Weideman, } \\
\text { M., 2015, 'Comparative } \\
\text { case study on website traffic } \\
\text { generated by search engine } \\
\text { optimisation and a pay- } \\
\text { per-click campaign, versus } \\
\text { marketing expenditure', } \\
\text { South African Journal of } \\
\text { Information Management } \\
\text { 17(1), Art. \#651, } 12 \text { pages. } \\
\text { http://dx.doi.org/10.4102/ } \\
\text { sajim.v17i1.651 }\end{array}$} \\
\hline \multicolumn{2}{|l|}{$\begin{array}{l}\text { Copyright: } \\
\text { (C) 2015. Th } \\
\text { Licensee: A } \\
\text { OpenJourn } \\
\text { licensed un } \\
\text { Commons } \\
\text { License. }\end{array}$} \\
\hline \multicolumn{2}{|l|}{ Read online: } \\
\hline 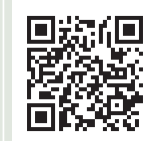 & $\begin{array}{l}\text { Scan this QR } \\
\text { code with your } \\
\text { smart phone or } \\
\text { mobile device } \\
\text { to read online. }\end{array}$ \\
\hline
\end{tabular}

Background: No empirical work was found on how marketing expenses compare when used solely for either the one or the other of the two main types of search engine marketing.

Objectives: This research set out to determine how the results of the implementation of a pay-per-click campaign compared to those of a search engine optimisation campaign, given the same website and environment. At the same time, the expenses incurred on both these marketing methods were recorded and compared.

Method: The active website of an existing, successful e-commerce concern was used as platform. The company had been using pay-per-click only for a period, whilst traffic was monitored. This system was decommissioned on a particular date and time, and an alternative search engine optimisation system was started at the same time. Again, both traffic and expenses were monitored.

Results: The results indicate that the pay-per-click system did produce favourable results, but on the condition that a monthly fee has to be set aside to guarantee consistent traffic. The implementation of search engine optimisation required a relatively large investment at the outset, but it was once-off. After a drop in traffic owing to crawler visitation delays, the website traffic bypassed the average figure achieved during the pay-per-click period after a little over three months, whilst the expenditure crossed over after just six months.

Conclusion: Whilst considering the specific parameters of this study, an investment in search engine optimisation rather than a pay-per-click campaign appears to produce better results at a lower cost, after a given period of time.

\section{Introduction}

The growth of the Internet has produced an important information resource during the last two decades that has advanced at a much faster rate than was previously envisaged. It took seven years to reach a $25 \%$ international market share $-70 \%$ faster than the development of the radio and $80 \%$ faster than the development of the telephone. This growth makes the Internet the fastest growing technology the world has ever encountered (Singh 2002). Boyes and Irani (2004:191) support this trend by claiming that the Internet had acquired 50 million global users in five years as opposed to the 38 years it took for radio and 13 years for television.

The implementation of the World Wide Web (WWW) has seen the world confronted with the concept of a website. Websites act as connection and communication points between the user and digital information. Therefore, most corporations (according to Akakandelwa 2011), organisations or institutions have been making efforts to launch themselves into the virtual world using this modern platform. The WWW is more than two decades old and, due to its complexity, its size is impossible to measure with regard to the number of websites or servers. It is claimed that, for January 2014, the nine most popular websites in the United States of America (USA) drew between 100 million and 370 million visitors each (Nielsen 2014). The WWW is a decentralised environment constructed and controlled by various people and access to it is less restricted than access to the common information media (Brunn \& Dodge 2001).

The base of Internet users is massive; hence, there is much interest in leveraging this user base for commercial gain. This commercial gain could be realised by ensuring that many thousands of users view a given website daily, with some of them being converted from browsers to buyers. It is generally accepted that the two types of interventions which could be implemented to increase the traffic to a website are search engine optimisation (SEO) and a paid campaign. However, 
no research could be found which compares the expenditure in a controlled environment with the value received from that expenditure for these two approaches. It is against this background that this study has originated.

The research problem on which this project was based is the fact that the respective value of the two marketing methods has not been directly compared, leading to resources being wasted on marketing. The purpose of this study was to compare these two categories to see how they produce traffic over a period of time, and to offset them against the expenditure.

\section{Literature review}

\section{Search engines}

According to Green (2000), a search engine is a search service that uses retrieval software called crawlers that examine websites and then index them in a database of website listings according to their relevancy. Search engines use their own indexing software and strategies to continuously traverse the Web, searching for the most up-to-date content possible. The indexing software (also referred to as spiders or bots) is responsible for visiting webpages following links between pages. The pages found are then analysed, parts are copied back to the site running the indexing software and added to the database for the purpose of including them in the search engine results (Weideman 2009).

Even though search engines use different algorithms to rank a webpage, they operate on similar principles. All search engines, primarily, strive to retrieve and display relevant results (webpages) that contain words or terms that match the user's search query (Green 2000; Guenther 2004:47).

Oppenheim et al. (2000:191) are of the opinion that, although search engines search a vast amount of information at impressive speeds, they are criticised on issues such as the retrieval of duplicate and irrelevant records owing to spamming techniques. The sheer mass of these irrelevant results is one of the main user complaints against search engines.

Much research has been done recently on search engines, the way they operate, the way users generate queries, and the way they affect our lives. Moreno and Martinez (2013) indicated that webpages can be designed to be both SEO and human friendly. This was confirmed by another study on the effect of usability elements on the way search engine crawlers view websites (Visser \& Weideman 2011).

In summary, the availability and use of search engines affect our lives on a regular basis through user interaction with results produced by them. It is now certain that the use of search engines, together with the power of advertising, plays a role in peoples' daily decisions on various aspects and is not limited to purchasing only.

\section{Search engine marketing}

Search engine marketing (SEM) is a strategy that makes use of the power of search engines to potentially attract millions of views per day to websites. Even academic universities need to consider how they should market themselves to prospective students as they are the paying clients (Weideman 2013). Crowley (2014) discusses some of these strategies, including SEO and tracking analytics, to determine user behaviour. Many systems are fighting for 'eyeballs'; these are users reading and responding to advertisements on websites. Social media has added to the frenzy through their advertisement offerings, although research has proven that it has not been all that successful. Barreto (2013) indicated that Facebook banner advertisements have less business value than recommendations from friends, possibly because of banner blindness. These ads (advertisements) were located outside the main viewing area first scanned by most users.

A recent study was done to determine the effectiveness of a search marketing campaign and the effect of print advertising on SEM (Olbrich \& Schultz 2014). It was found that the budget and the degree of keyword matching had the largest effect on the yield in business gained, followed by the click-through rate and the bid amount. This result seems to indicate that SEM needs to be planned with care as a larger budget might reduce expenditure on other marketing efforts. This fact supports the current study. SEO and pay-per-click schemes (PPC) are generally considered to be the two main categories of SEM which are to be investigated.

\section{Pay-per-click}

PPC schemes, producing non-natural rankings, are systems which display advertisements on a search result screen, co-located with organic results but ranked separately. The location of these advertisements is normally to the right and above the organic search engine listings (Chen et al. 2011). This sharing of the prime real estate space on the user's screen has caused some problems for users. No longer can they simply evaluate the quality of answers based on which answer is listed the highest on the result screen as they have to also consider the ranking difference between organic and paid results. Even libraries have found this to be an obstacle for their users (Moxley, Blake \& Maze 2004). However, many industries, particularly the tourism sector, have been making extensive use of this marketing opportunity. In some cases even small businesses went to extremes to do research to identify the better search engine PPC scheme to use (Kennedy \& Kennedy 2008). At the same time, the 'newness' of this form of marketing initially scared off other smaller businesses for example some smaller hotels did not make use of PPC (Murphy \& Kielgast 2008).

PPC, as the name suggests, charges the advertiser the bid amount every time an Internet user clicks on an advertisement. The keywords all have different competition ratings and the more popular a keyword, the higher the cost 
per click would be (Chen et al. 2011). A recent study on the value of the bid price per keyword for a new PPC campaign determined the best of a number of methods to determine this price (Nabout 2015). This study confirms the importance of financial expenditure, which could easily grow beyond what a company decided they could spend on a marketing campaign.

The PPC ranking system operates in stark contrast to the value associated with the quantity and quality of inlinks, in other words SEO (Thelwall 2001). In the past Google specifically used a simple formula to determine the ranking of PPC results: Rank = Bid price X Quality Score (Sagin 2013). The bid price is the amount the advertisement owner is prepared to pay per user click on the ad, and the quality score is Google's interpretation of the quality of the landing page. However, in October 2013 Google announced a third factor, namely ad extensions (Mancuso 2013). Where two competing advertisements achieve an equal score, the use of ad extensions is used to determine the highest ranker.

A recent study was done on the relationship between print and search engine advertising (Olbrich \& Schultz 2014). The results proved that print advertising did not directly affect the number of advertisements impressions produced by the search engine. However, there was an indirect relationship between print advertising and the number of conversions indicating that e-commerce marketers cannot ignore the traditional advertising methods and focus only on SEM. Since exposure through PPC requires constant and accumulative expenditure, past research has also focused on maximising this expense. The performance of PPC advertisements is crucial in recapping the expense, hopefully bypassing it to provide a profit. Another recent study determined the role of ranking of these advertisements, branding, and the role of the device used to search (Gupta \& Mateen 2014).

In summary, PPC has been a successful business model. In the case of Google, it has produced the bulk of its profits over the years, playing a major role in its financial success (Kumar \& Kohli 2007). At the same time, an e-commerce business running PPC schemes on multiple keywords across many campaigns is advised to budget for specialised staff to manage these campaigns. Still, some authors actually prescribe that PPC is a better way to spend marketing dollars than SEO (Sen 2005).

\section{Search engine optimisation}

SEO is a method that uses data observation and marketing research to identify the most suitable keyword for a website (Malaga 2010). However, it requires a base of knowledge to implement, such as how to choose keywords and how to use keywords in order to enhance a website's ranking, etc.

There is a need for any e-commerce business to be ranked highly with search engines (Kent 2012). Another author states that to increase the volume of traffic to individual websites from search engines, SEO must be considered and invested in (Kisiel 2010). For successful SEO there are many concepts that need to be understood and applied; some of these are discussed later. The ultimate goal of SEO is to increase a website's ranking with search engines, thus increasing the traffic to the website, which should result in increased sales (Lee 2010; Lee, Chen \& Wu 2010; Lee \& Lin 2011).

Lately, much research has been done on the visibility of content to search engine crawlers. Onaifo and Rasmussen (2013) found that the principles of SEO can, and should, be applied to increase the visibility of library content to search engines. A number of elements affect SEO; it is not just a case of implementing a simple set of rules, thereby ensuring high visibility. Some of these elements are listed below.

Another recent study considered the value of using search query data to obtain business information. Search query data is much more recent than, for example, business reports published at the end of a financial year. A significant correlation was found between business performance and position and search query data (Vaughan 2014). This kind of timely information could be used to predict business performance, leading to financial gains.

It is clear that both SEO and PPC could play a role in marketing a website to the search engine crawlers. The purpose of this study was to determine how much traffic each of SEO and PPC produces and to measure and compare the expenditure in each case.

Some of the aspects of SEO are considered below. They are all discussed with regard to the components of a webpage over which the website owner has direct control.

\section{Header tags}

Metatags are elements of a webpage that are mostly optional, invisible to the casual browser, but which could affect the way a crawler views a webpage. One of these is the $\mathrm{H}$ (Heading) meta tag.

A Web designer can choose whether or not to highlight headings inside a block of text on a webpage. To this effect, there are six levels of heading tags. $\mathrm{H} 1$ is the most important (biggest text); H2 is slightly less important, down to H6 which is the least important. Some search engines recognise the use of header tags as a safe method to weight keywords, owing to its connection with a heading of a paragraph. Henzinger, Motwani and Silverstein (2002:9) state that the higher the importance of the headings, the more weight a search engine could assign to a given webpage. For example, text in an $<\mathrm{H} 1>$ would appear prominently on a webpage and therefore some search engines could see it as safe to assign a high weight to the text in that heading.

Research by Craven (2003) to determine the relevant weight of meta tags indicates that the $\mathrm{H} 1$ (heading 1) and $\mathrm{H} 2$ (heading 2) tags are the second and third most highly 
weighted (after the TITLE tag) of all the meta tags. As with Microsoft Word, the hypertext mark-up language (HTML) has built-in styles for headings to differentiate between importance levels of text that are usually used to break up text into paragraphs. The different options allow the designer to develop large and bold text in an HTML document, marking the beginning of a new paragraph or section (Henzinger et al. 2002:9).

\section{Image filenames}

Search engine crawlers cannot interpret the content of an image, a video or an audio file. The designer has to provide text-based information to allow the crawler to make some association between this type of file and its contents (Weideman 2009). For still images, the name of the file is the most obvious way of establishing this association. A simple experiment can prove that the name of an image file does play a role in its visibility. When doing an image search on Google or Bing for the term 'rolls royce' for example, page after page of images of this car are produced. Upon closer inspection of the first result page, virtually every image has those two words as part of the file-name.

\section{Image alternative tags}

ALT (alternative) tags are used to display text in the place of an image on a webpage if graphics are turned off. The ALT text will also display if a user places his or her mouse pointer over an image for a few seconds. Currently, automated crawlers can read only text elements within a webpage and are unable to read multimedia elements, as discussed earlier. For this reason, it is of importance to apply ALT tags, where possible, that accurately describe the graphics on the webpage (Hubbard 2004).

By implementing ALT text within a webpage, the developer ultimately caters for users who turn graphics off to increase loading speed. Without the use of ALT tags a site could become impossible to navigate when graphics are turned off. The use of ALT tags also provides the ability to cater for users with a visual impairment. Voice-output screen readers (benefiting those users) will not 'read' a non-text element (Oppenheim et al. 2000:204), but will do so if an ALT element is provided. Ironically, the implementation of techniques to allow the visually impaired to better interpret website contents could also play a major role in improving the user experience of other users, as well as the way crawlers interpret webpages.

\section{Metadata}

Another meta tag which plays a role in visibility is the TITLE tag. It is also invisible as part of the body text of a webpage being displayed, but it is often displayed on a user screen as part of search engine results. Search engines often claim that the presence of a well-written TITLE tag can positively influence a webpage's visibility (Guenther 2014).
In summary, only a few of the many elements affecting the crawler visibility of a webpage have been discussed. There are many others (keyword usage, HTML file-names, links, etc.), as well as a long list of negative elements that should specifically not be implemented (Weideman 2009).

\section{Methodology}

Data were gathered from a real-life website where first the one (PPC) and then the other (SEO) of the marketing approaches were followed exclusively. Usage behaviour and statistics were recorded and analysed in an attempt to compare the expenditure with the gain from each approach.

A company in Cape Town, South Africa, manufactures PVC, polypropylene and leather promotional and stationery products. The company's name is not listed; for the purposes of recording they will be named XYZ. The company invested in PPC from May 2010 to May 2011 in an attempt to drive traffic to the website. During that time no SEO implementation was done on the website. Each month XYZ spent, on average, R3000 on PPC. However, after the PPC campaign was terminated, they paid a once-off fee of R19 000 for the SEO project.

The XYZ concern is a relatively small company. Considering that they have a typical monthly website traffic figure of hundreds as compared to millions for large companies, their business model must be sound to run a successful e-commerce concern. The most important requirement of the client was that their website remained optimised in such a way that it could lead to sales. The authors did a detailed investigation of the $\mathrm{XYZ}$ website, identifying elements that could be improved through SEO with the estimated shortterm cost it may entail.

The following elements which needed improvement were identified:

- Header tags (were not being used).

- Image filenames (were inappropriate and nondescriptive).

- Metadata (was outdated).

- Alternative tags (were inappropriate and nondescriptive).

- Product descriptions (were too short or non-existent).

- The bounce rate (was too high).

\section{Header tags}

All the headings on the $\mathrm{XYZ}$ website were placed in strong tags. Best practice prescribed that all strong tags be replaced with $\mathrm{H} 1$ and $\mathrm{H} 2$ Tags. This would imply that the authors would have to inspect every one of the 55 webpages and either write new $\mathrm{H} 1$ tags, or rewrite the existing ones.

\section{Image filenames}

Some of the image filenames did not contain relevant keywords. An example of this was '_MG_2174.jpg'. Again, 
best practice was that these filenames be renamed with appropriate keywords that reflect the objects on each image. A total of 246 images were found and renamed in the 55 HTML pages.

\section{Metadata}

Throughout the year the website was updated with new products, whilst older products were removed. However, the metadata was not updated accordingly. It was recommended that the metadata of all 55 HTML pages be updated to reflect the new content. This was done, and it included updating the TITLE-, DESCRIPTION- and KEYWORD tags of all 55 HTML pages.

\section{Image alternative tags}

Some of the ALT tags of the images were too long. These ALT tags, in accordance with best practice, needed to be shortened and rewritten to contain relevant keywords that reflect the images that they are associated with. There were a total of 256 images whose ALT tags were reviewed and rewritten.

\section{Product descriptions}

Some of the products listed on the XYZ website were identified by only one short sentence. It was decided, based on best practice, that all product descriptions be rewritten to have at least two to three descriptive sentences each. Sixty four of the 128 products did not have sufficient descriptive text and were subsequently rewritten. The remaining 64 descriptions were also reviewed to ensure that they contained relevant keywords.

\section{Bounce rate}

The XYZ website had a bounce rate of $48 \%$, where a lower figure is considered to be better (Plaza 2009). In industry, a bounce rate of $30 \%$ is considered to be a breakpoint; higher than $30 \%$ is 'bad' and lower is 'good'. It was necessary that the homepage text be reviewed with the aim to reduce the high bounce rate. However, the bounce rate is not an element that a Web developer can improve by doing coding updates or any other direct actions. It is a figure which will decrease (i.e. improve) as users spend more time on webpages as a result of other elements described here being put into place.

\section{Project plan}

The project was thus split into three stages:

- Throughout June 2011 the header tags were modified.

- Throughout July 2011 the image filenames and image ALT tags were modified.

- Throughout August 2011 the product descriptions, copy, and metadata were modified.

These timescales appear in the figures following, to indicate the effect of each alteration.

\section{Results and interpretation Header tags}

The effect (if any) of the header tag improvement, as discussed earlier, was measured by viewing statistics on website usage as from when the header tags were redone. Refer to Figure 1.

The company stopped their PPC campaign on 31 May 2011. The immediate effect of this action was a drop in total traffic by $15.42 \%$ (1130 vs 1336) when comparing June 2011 with May 2011. The authors then proceeded to review and modify all headings on the website. This process involved modifying the CSS file and defining the Header Tags. There were 244 instances where strong tags were used, and all of them were replaced with $\mathrm{H} 1$ and $\mathrm{H} 2$ tags.

Also, the headings were modified to include appropriate keywords. The authors ensured that each page only had one instance of the $\mathrm{H} 1 \mathrm{tag}$, which is considered the most important of the heading tags. The work was conducted throughout June 2011 and was completed in the final week of June 2011. It must be noted that all the work was completed on the live website. As the authors progressed a slight increase in traffic in the second week of June 2011 was noted.

It must also be noted that 01 May 2011 and 02 May 2011 were Worker's Day and a public holiday respectively in South Africa. These two calendar events would have had a negative impact on the statistics as the biggest part of the workforce would not be at work on those days. However, this pattern repeated the next month: 16 June 2011 and 17 June 2011 were Youth Day and a school holiday respectively. These two calendar events would have had a similar effect on the figures of June 2011. Also, during 25 June to 18 July 2011 the schools in South Africa were closed for recess which would also have had a negative impact on the June 2011 statistics.

By this time half of the 244 instances of strong tags were replaced by either $\mathrm{H} 1$ tags or $\mathrm{H} 2$ tags. The fact that the authors saw an increase in organic traffic was somewhat unexpected, since it can take search engines up to a month (Zuze \& Weideman 2013) to re-index and rank webpages after significant changes have been implemented. From the author's point of view this highlights the importance search engines place on Header tags. For any website it is a simple matter to assign header tags to headings. The website, from a search engines perspective, was seen in a more favourable position because of the above action taken.

\section{ALT tags}

The effect of the updating of the ALT tags was also measured by viewing the relevant statistics - see Figure 2 .

The modifications of the image ALT tags were completed in the final week of July 2011. Whilst performing this task 


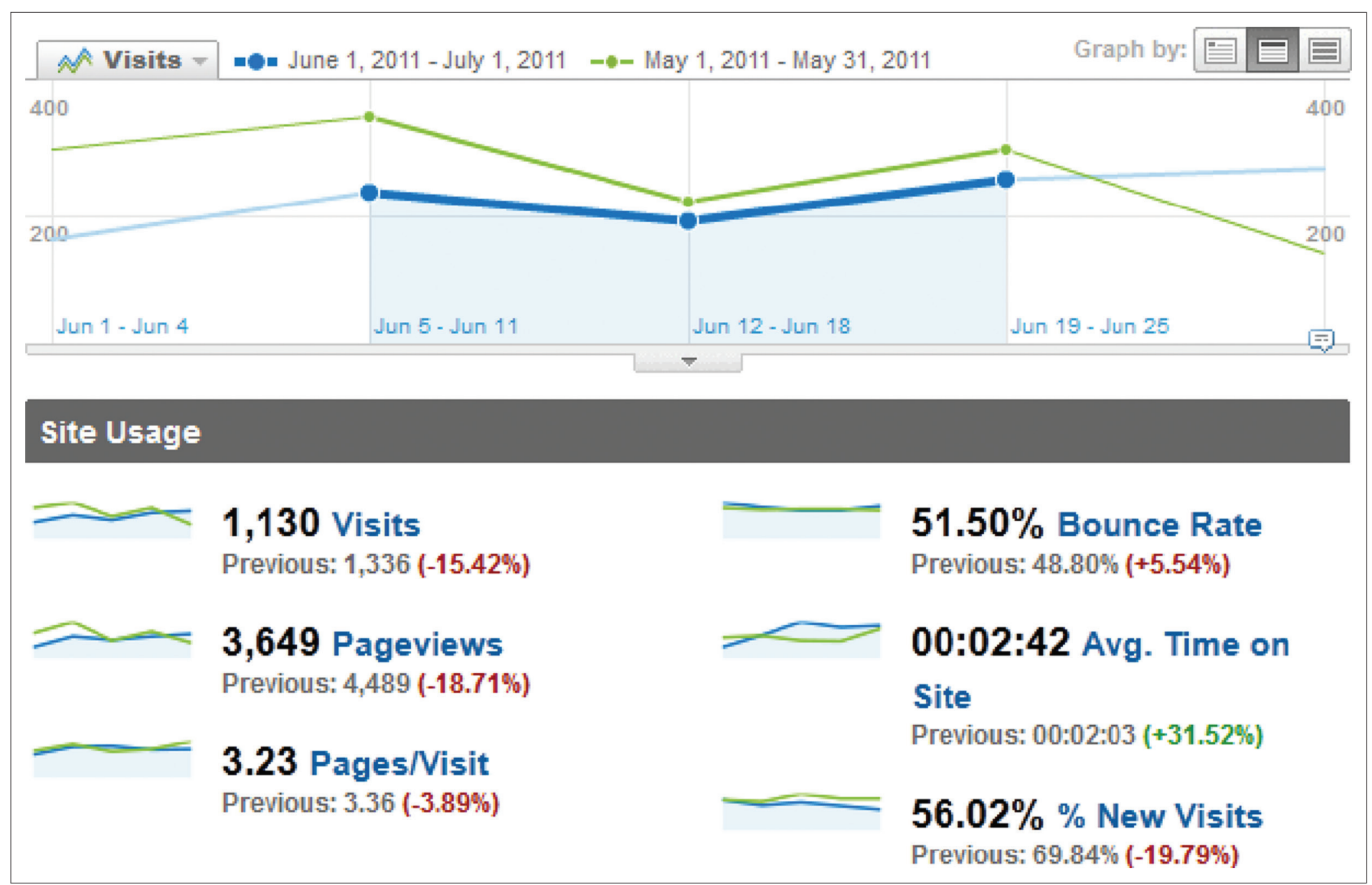

FIGURE 1: Effect of header tag improvement on website visitations.

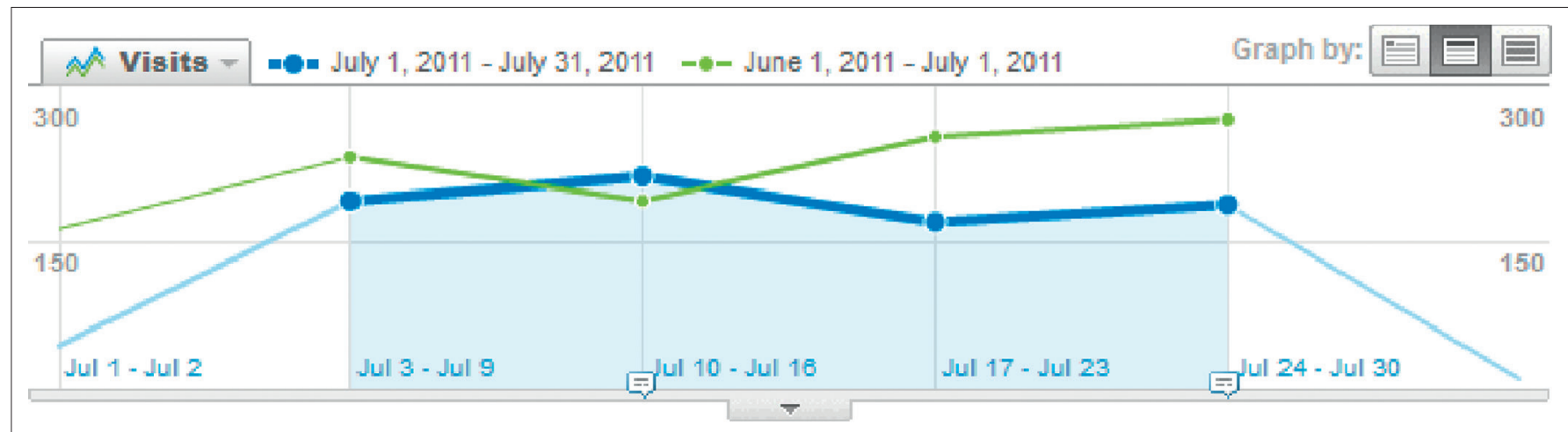

\section{Site Usage}

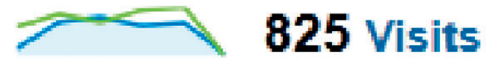

Previous: 1,130 (-26.99\%)

2,785 Pageviews

Previous: 3,649 (-23.68\%)

\subsection{Pages/Visit}

Previous: $3.23(+4.54 \%)$

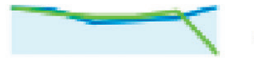

$46.67 \%$ Bounce Rate

Previous: $51.50 \%(-9.39 \%)$

00:02:06 Avg. Time on

Site

Previous: 00:02:42 (-22.21\%)

$62.06 \% \%$ New Visits

Previous: $56.02 \%(+10.79 \%)$ 


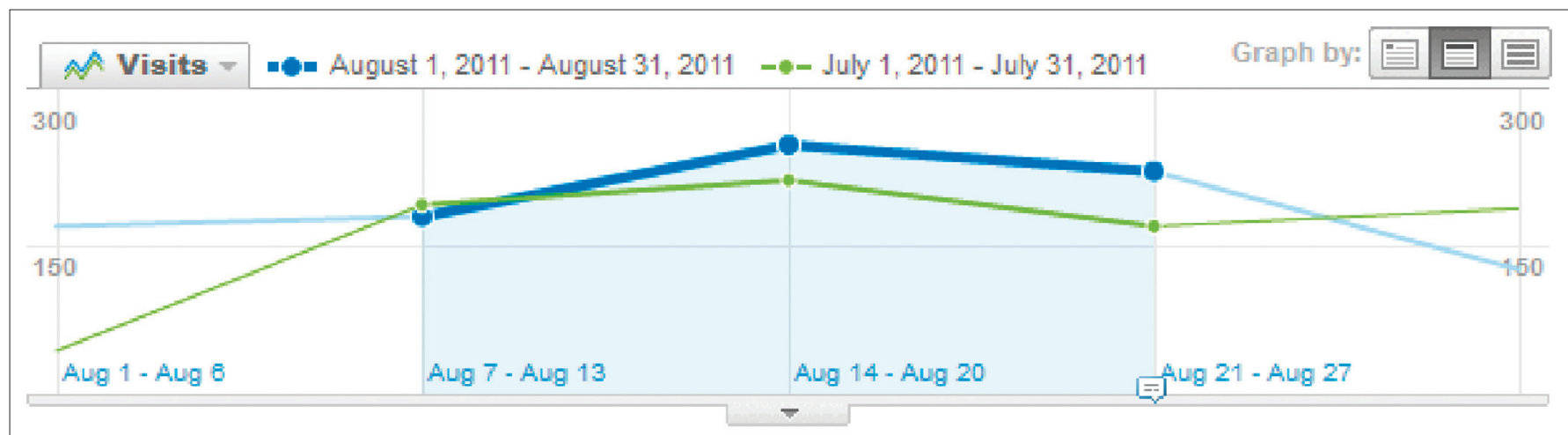

\section{Site Usage}
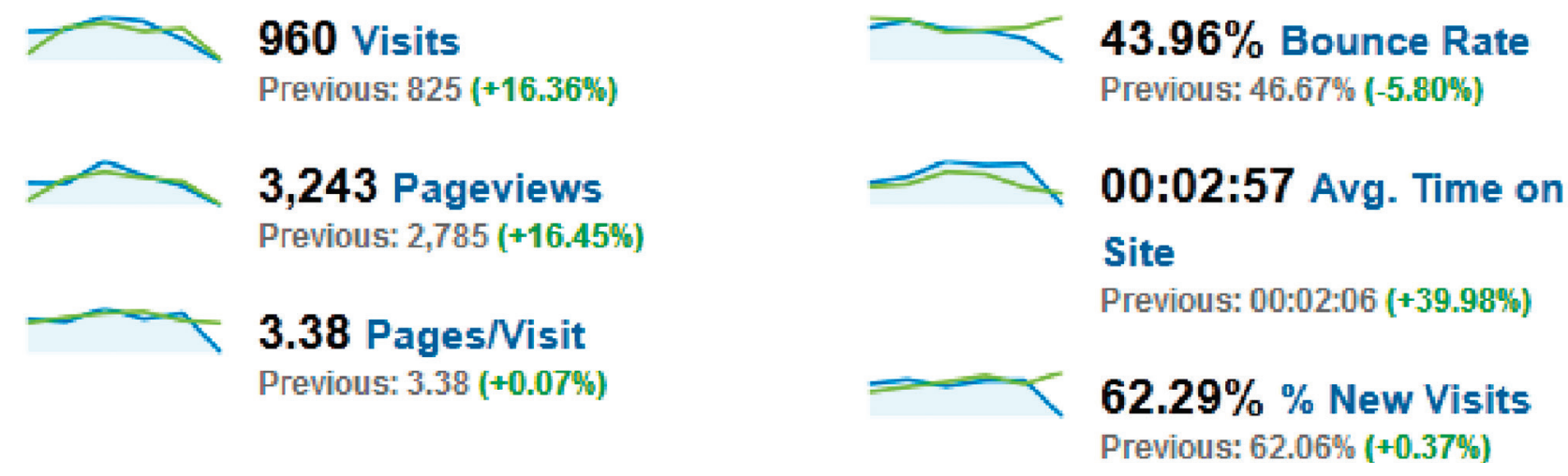

FIGURE 3: Effect of product descriptions, content and metadata improvement on website visitations.

the authors observed a slight decrease in traffic from the second week to the third week of July 2011. However, a slight increase in total traffic followed the initial decline as the month of July 2011 drew to a close. By this time, the total number of visitors dropped from 1336 (May 2011) to 825 (July 2011). As mentioned previously, during the month of June the holiday events would have impacted on these figures. Some users at that time would have gone on family holidays, reducing Internet activity to an extent.

It is expected to note decreases in traffic when extensive work is being performed on a website. Search engines take note of content changes after which they have to re-index and rank the individual webpages. This process can take anything from a few days to months. The increase by the end of July 2011 was also, in a sense, unexpected as the authors argued that the process of re-indexing and ranking would take longer than it did. This increase also indicates the value basic SEO elements can have on a website's ranking.

\section{Body content}

The role of body text and the use of keywords have been noted many times in previous research. As mentioned above, sections of this body text had to be rewritten and the graphs of Figure 3 indicate the effect of these changes.
A lack of regular updating of HTML metadata content was noted in the webpages of the company. Whilst descriptive text in the body was updated, the relevant metadata was simply left with the original content, leading to a severance of the connections between these two elements.

Care was taken to ensure that all three meta-elements were rewritten according to Google's guidelines. The new version contained relevant keywords and reflected the product that it related to. This work was completed in the last week of August 2011.

The August 2011 total traffic increased compared to July $2011(16.36 \%)$. This indicated to the authors that Google was starting to re-index the text website with the modifications. It must also be noted that the schools in South Africa were closed for recess between the periods of 24 June 2011 and 18 July 2011, which would have negatively impacted the statistics for the month of July 2011. However, August 2011 did have two public holidays on 08 August 2011 (school holiday) and 09 August 2011 (Women's Day). These two calendar events would have had a similar negative effect on the August 2011 figures.

A relative simple update to the content, and ensuring that the metadata was reflective of the new content, produced a significant increase in website traffic. This was mostly because of the presence of relevant, unique, keyword rich and regularly updated content. This increase in traffic confirms 


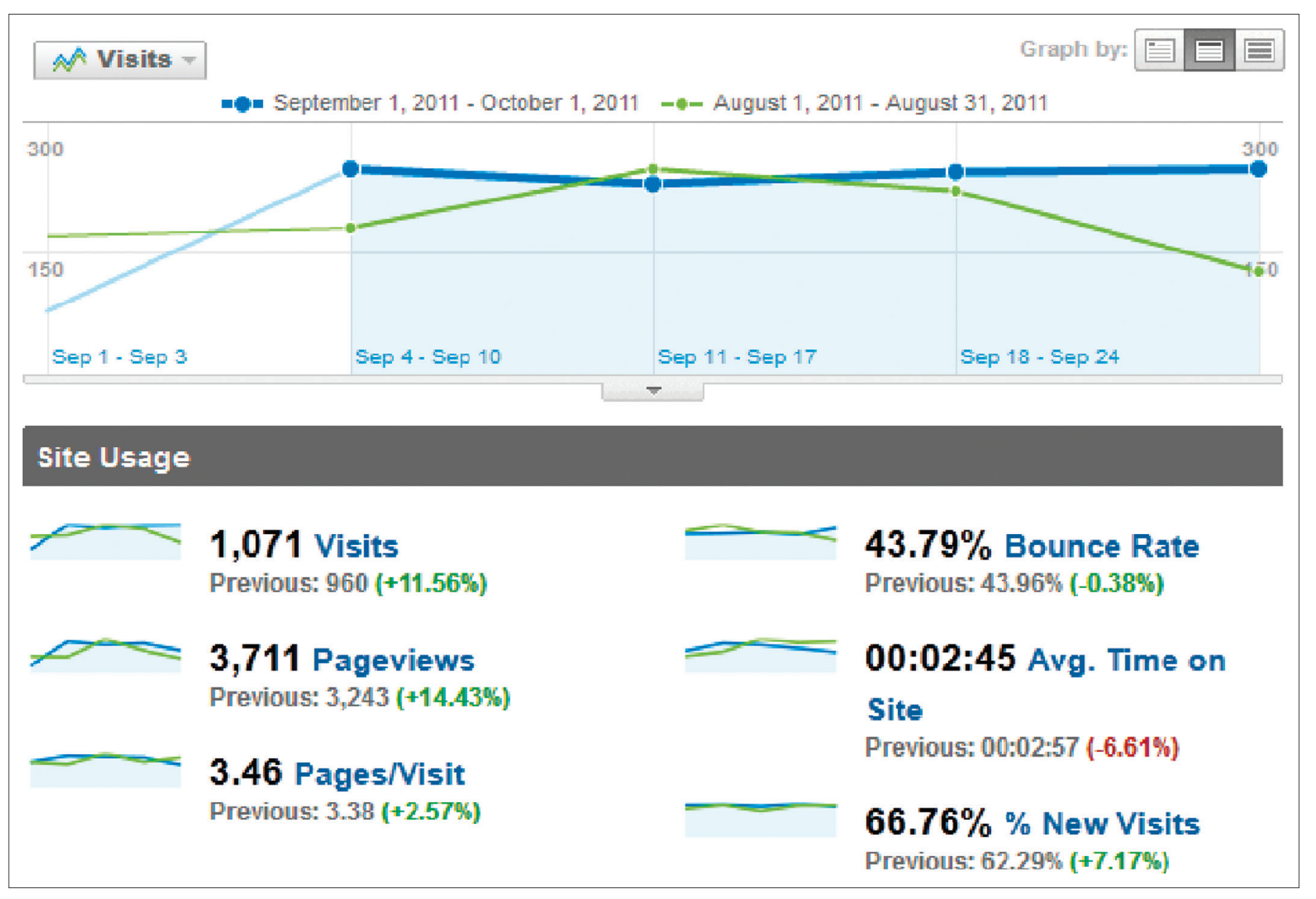

FIGURE 4: Total website traffic: September 2011 compared to August 2011.

this conclusion and website authors should seriously consider this crucial aspect of a website.

\section{Overall traffic trends Month 1}

Next, two one-month periods are compared to determine whether a trend is evident. See Figure 4.

During the month of September 2011 no work was conducted on the test website. In this time, the total traffic increased further compared to August 2011; $11.56 \%$ in total. Although August 2011 had not quite reached the traffic levels of May 2011, which included the PPC traffic, the data looked promising. Also note that August 2011 had two calendar events that would have negatively impacted the results for August 2011, as noted earlier. Furthermore, September 2011 also had one event on 24 September 2011 when South Africans celebrated Heritage Day.

By this time it was safe to assume that Google had indexed all the on-site changes. It was evident that all the website's pages were being re-indexed and ranked. However, the continuing climb in traffic indicated that rankings were indeed improving and more and more users were finding the website via Google's search result pages. This has to be seen against the fact that no further investment in PPC was done after campaign shutdown in May 2011.

\section{Month 2}

In October 2011 the authors continued to monitor the results and noted another slight increase in total traffic $(1.21 \%)$. This was an indication that Google had completed the re-indexing of the modified test website. By this time the website traffic had increased from 825 visits to 1084 (31.4\% increase) in a period of four months. It should be noted that, in October 2011, the schools in South Africa closed for recess from 01 October 2011 to 10 October 2011. This would have had a negative impact on the October 2011 data. Also, as mentioned before, Heritage Day was celebrated on 24 September 2011.

\section{Annual comparison}

Finally, a year on year comparison is performed - see Figure 6.

In Figure 6 the authors compare the period 01 June 2011 to 31 October 2011 (no PPC included) to 01 June 2010 to 31 October 2010 (PPC traffic included). In June, the data regarding website traffic for the two years appear similar, however a sharp decrease in traffic can be observed when the PPC campaign was shut down and the modifications to the website started. By August 2011 the traffic already started increasing to just below the levels of the previous year after the header tags, image file names and image ALT tags were modified. Then, in August 2011 when the product descriptions, new homepage content, and 


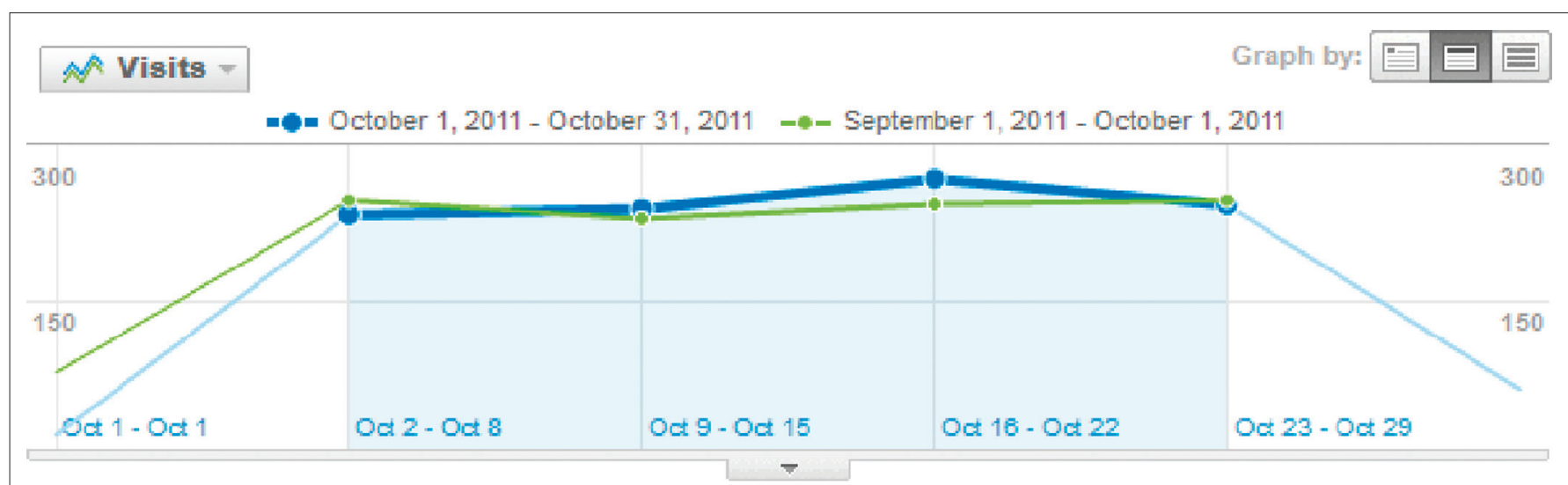

\section{Site Usage}

\section{$\longrightarrow 1,084$ Visits \\ Previous: 1,071 (+1.21\%)

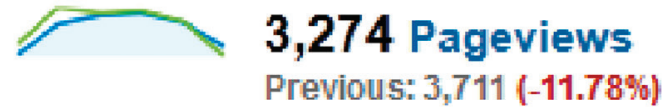 \\ 3.02 Pages/Visit \\ Previous: $3.46(-12.83 \%)$}

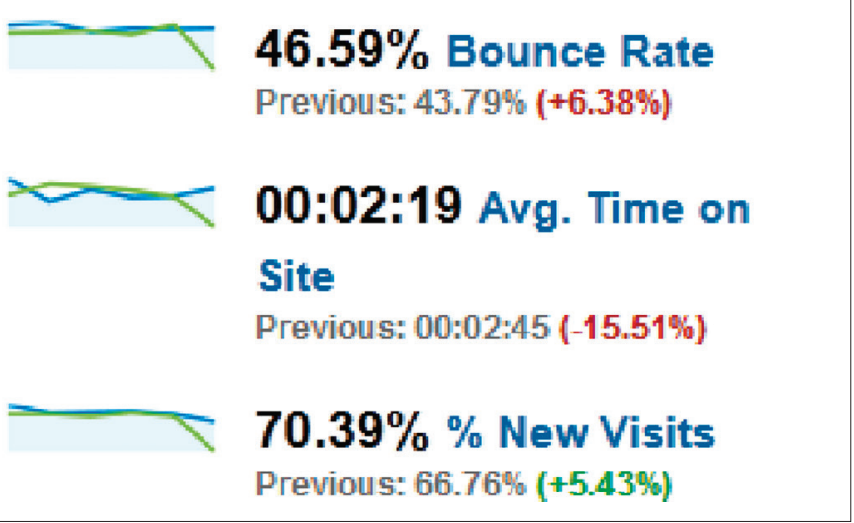

FIGURE 5: Total Traffic October 2011 compared to September 2011.

metadata were concluded the traffic increased further. By end of September 2011 the total traffic had increased to levels higher than the previous year, which included the PPC traffic.

\section{Final traffic or expenditure summary}

The results of this study are best described by summarising traffic to the XYZ website during the two test periods, whilst comparing it to the expenditure. Table 1 summarises the relevant figures.

The date column lists the date of measurement of both traffic values and the expenditure of company XYZ on SEM. 'Traffic $\mathrm{PPC}^{\prime}$ lists the number of visitors for the period originating from all search traffic; direct, referral and PPC sources. However, the actual figures for November 2010 until May 2011 were not available, and these figures were taken to be the average of the preceding months (718).

The 'Traffic SEO' column contains the number of visitors for the relevant period, all of which is search traffic. However, by this time the PPC campaign had been terminated, so part of the source is SEO-generated traffic. The 'Expenses Original' column is a summary of the SEM expenditure of the $\mathrm{XYZ}$ Company, being R3000 per month spent on PPC for 11 consecutive months. In May 2011 there was no expenditure, since the PPC campaign was terminated. Then, in June 2011, an amount of R19 000 was paid (once-off) to do the SEO as agreed.

Finally, the 'Expenses Adjusted' column is simply the 'Expenses Original' figure divided by 21. The figure of 21 was chosen as a scale-down factor to bring the Rand values in line with the other figures in the table. This would ensure that graphs of these values plotted on the same scale (see Figure 7) would be comparable in amplitude.

A graphical presentation of the relevant figures as noted above is done in Figure 7.

An analysis of the graphs in Figure 7 is required. The PPC graph indicates that the amount of search traffic had stabilised over the 12 month period from June 2010 to May 2011. Since this component consists of three parts and the split is unknown, it cannot be determined what the exact contribution of PPC was to the monthly figure. However, it is assumed that it must have been substantial considering the steep drop in traffic in the months (June and July 2011) directly following the termination of the PPC campaign.

The SEO graph of Figure 7 again lists all search traffic to the website, but this time with the PPC component having been 


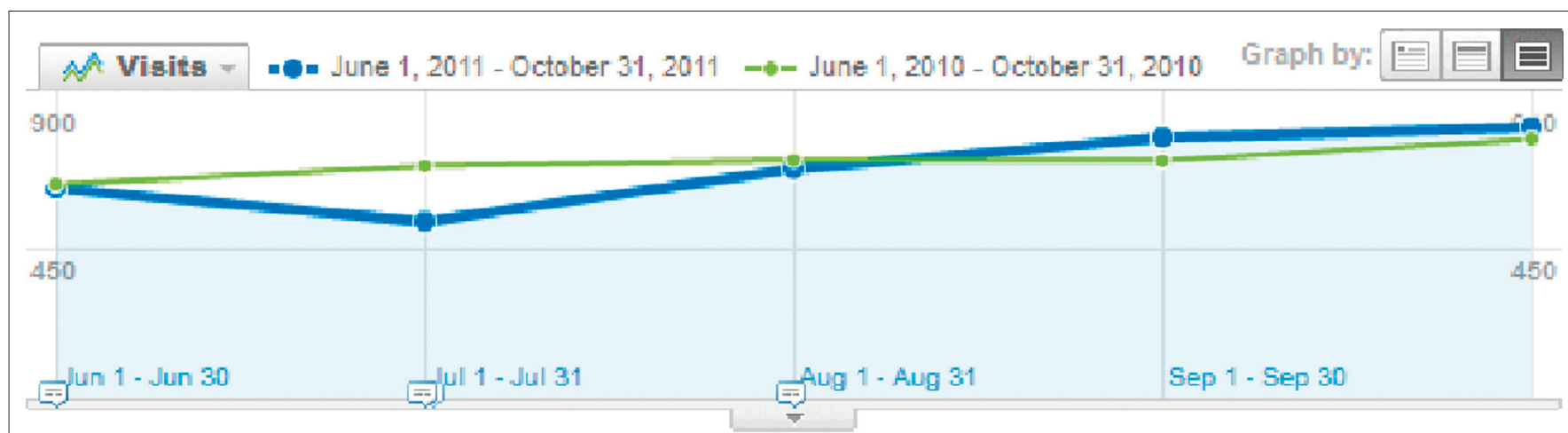

\section{Search sent 3,485 total visits via 8 sources}

Show: non-paid | total| paid

\section{Site Usage Goal Set 1}

\begin{tabular}{l|l} 
Visits & Pages/Nisit \\
$\mathbf{3 , 4 8 5}$ & $\mathbf{3 . 3 1}$ \\
Previous: 3,588 & Previous: 3.80 \\
(-2.87\%) & (-12.94\%)
\end{tabular}

Avg. Time on

Site

00:02:36

Previous: 00:02:02 (27.04\%)

\begin{tabular}{|c|c|c|c|c|c|}
\hline & Source $=$ & None & Visits $\quad \downarrow$ & Individual Source: Wisits & $\begin{array}{l}\text { - compared to Jun } 1,2010 \\
- \text { Oet } 31,2010\end{array}$ \\
\hline 1. & google & & 2,957 & $-6.51 \%$ & \\
\hline 2. & bing & & 41.3 & & $34.53 \%$ \\
\hline 3. & search & & 52 & $-44.60 \%$ & \\
\hline 4. & yahoo & & 33 & & $175.00 \%$ \\
\hline 5. & yandex & & 23 & & $100.00 \%$ \\
\hline 6. & aol & & 4 & & $33.33 \%$ \\
\hline 7. & images.google & & 2 & & $100.00 \%$ \\
\hline 8. & ask & & 1 & $-88.89 \%$ & \\
\hline
\end{tabular}

FIGURE 6: Year on year comparison: 01 June 2011 - 31 October 2011 compared to 01 June 2010 - 31 October 2010.

replaced by the newly introduced SEO component. The initial drop over the first two months is owing to the SEO campaign taking time to influence rankings and therefore traffic. However, as from the third month into the SEO section, the graph shows a continued rise indicating a growing trend in traffic volumes. This resulted from the fact that search engine crawlers had started visiting the site, indexing the new content, and their algorithms had started giving the site an ever increasing rank in the result listings. The rising trend appears to flatten towards the last recorded month, but without more figures this trend cannot be confirmed past the last recorded month.

Finally, the expenses of XYZ to achieve this increase in traffic need to be put into perspective - refer to the ' $R$ ' line on Figure 7. At a fixed rate of R3000 per month, XYZ had spent 
TABLE 1: Comparative traffic during two periods.

\begin{tabular}{lcccc}
\hline Date & Traffic PPC & Traffic SEO & Exp. Adj. & Exp. Orig. \\
\hline Jun-10 & 650 & - & 142.8571 & 3000 \\
Jul-10 & 706 & - & 142.8571 & 3000 \\
Aug-10 & 723 & - & 142.8571 & 3000 \\
Sep-10 & 721 & - & 142.8571 & 3000 \\
Oct-10 & 788 & - & 142.8571 & 3000 \\
Nov-10 & 718 & - & 142.8571 & 3000 \\
Dec-10 & 718 & - & 142.8571 & 3000 \\
Jan-11 & 718 & - & 142.8571 & 3000 \\
Feb-11 & 718 & - & 142.8571 & 3000 \\
Mar-11 & 718 & - & 142.8571 & 3000 \\
Apr-11 & 718 & - & 142.8571 & 3000 \\
May-11 & 718 & - & 0 & 0 \\
Jun-11 & - & 639 & 904.7619 & 19000 \\
Jul-11 & - & 536 & 0 & 0 \\
Aug-11 & - & 696 & 0 & 0 \\
Sep-11 & - & 792 & 0 & 0 \\
\hline Oct-11 & - & 822 & 0 & 0 \\
\hline
\end{tabular}

PPC, pay-per-click; SEO, search engine optimisation; Exp. Adj.; Expenses Adjusted; Exp. Orig.; Expenses Original'.

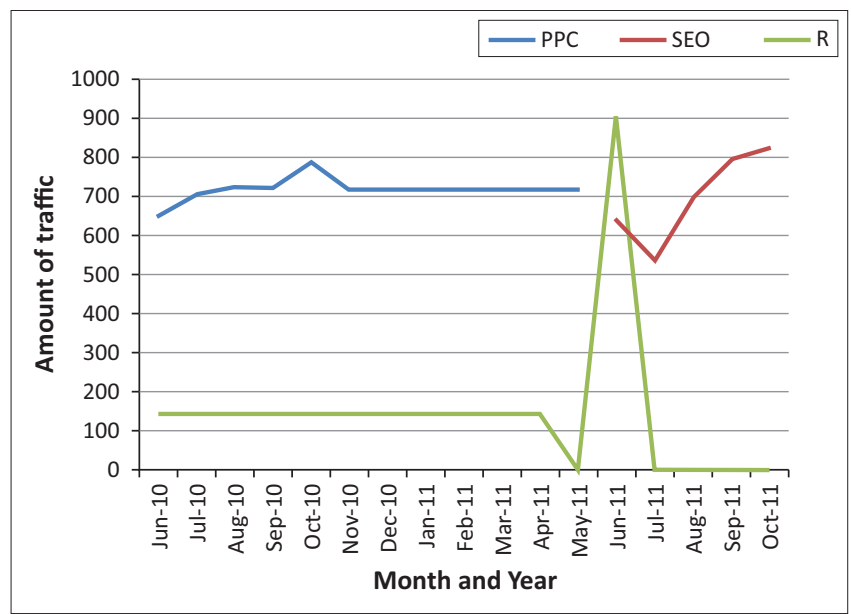

FIGURE 7: Summary of traffic versus expenditure.

R33 000 over the 11 month period in an attempt to maximise the number of visitors to their site. This expenditure played a large part in achieving the traffic volumes listed as the PPC line as noted above. During June 2011 there was a sharp increase to R19 000, but this was a once-off expenditure. After that time it dropped to zero for the rest of the recording period.

It should be noted that the traffic volume during the SEO period had bypassed the highest level achieved during the PPC period after only three months of running on SEO. This occurred whilst the average monthly PPC expense of R3000 compared well to the R3800 (R19 000/5) average per month spent on SEO for this short period. However, this R3800 average figure is for only five months as compared to the PPC figure of 11 months. The average cost for SEO, if calculated further, would decrease dramatically as follows:

- November 2011: R3167 per month

- December 2011: R2714 per month

- May 2012: R1727 per month
In both cases, after 11 months the PPC expense would still be R3000 per month with the SEO averaging out at R1727 per month. This trend of downward spiralling costs for SEO would continue. At the same time, if the SEO graph is extrapolated, it can be expected that the traffic volumes could increase past those achieved during the PPC period.

It should be noted that in a real-life SEO campaign there will be further expenses past the initial layout, but not necessarily of the monthly recurring type. In the time period of this case study there were none, bar the initial amount. However, a study over a much longer period of time is needed to do a long-term comparison. It is likely that the longer an SEO campaign is running, the lower the average monthly costs will become.

Limitations of this study include that the data were obtained from a relatively low-traffic site. Also, data across a longer period of time would provide a clearer trend. Finally, a comparison was done on the traffic generated from certain marketing expenses only, not the profit eventually generated by that traffic.

\section{Conclusion}

An existing commercial website (that of company XYZ) was considered as the central object of this research project. An experiment was done on the XYZ website to start implementing SEO immediately after the PPC was terminated. At the same time, monitoring was done of traffic to the website and of other relevant analytic measures. The SEO was done based on industry best practice supported by academic research.

The owners had been spending 'marketing dollars' on this website, using firstly, only one of the two main types of SEM for a period: PPC. The main disadvantage of PPC is that expenditure has to be consistent for results to appear; the moment a PPC budget is cut, the resultant traffic drops to zero immediately. Therefore, the overall PPC expenditure should be calculated from the monthly expenditure; in the case of XYZ, R3000.

After the PPC campaign was terminated, XYZ spent R19 000 once-off on SEO. This amount was for the implementation of the elements as listed under 'Methodology' above. As noted from the literature, where PPC produces immediate ranking improvements once payment has been arranged, SEO takes longer to affect rankings. This is mostly due to the waiting period for search engine crawlers to visit or refresh their copy of the website content.

When these expenditure figures are compared, it can thus be claimed that, after 6.33 months, the expenditure on the two systems for XYZ would have been the same. From this point in time onwards, SEO would continue to provide a growing return on investment over $\mathrm{PPC}$, assuming that no further expenses would be required for SEO. 
In conclusion, it can be claimed that, in this specific case, SEO provides a better investment than PPC. It is also predictable that this advantage will increase as time goes by. It should also be noted that traffic to a website on its own is not the only indicator of success. A high conversion rate, leading to more revenue generated, and eventually leading to increased profit would be the final indicator of the success of an e-commerce website. However, owing to the sensitivity of company financial information, this kind of evidence will be harder to come by and use as proof.

\section{Acknowledgements Competing interests}

The authors declare that they have no financial or personal relationships which may have inappropriately influenced them in writing this article.

\section{Authors' contributions}

Both W.T.K. (Cape Peninsula University of Technology) and M.W. (Cape Peninsula University of Technology) worked together in conceptualising the research work, completing the literature survey and reference hunting, doing the writeup and checking results. W.T.K. gathered and summarised the data, checked accuracy and did the write-up of the skeleton of the whole article, specifically the results section. M.W. did the conclusion, abstract, proofreading, editing and overall checking.

\section{References}

Akakandelwa, A., 2011, 'An exploratory survey on the SADC e-government web sites', Library Review 60(5), 421-431. http://dx.doi.org/10.1108/ 00242531111135317

Barreto, A.M., 2013, 'Do users look at banner ads on Facebook?', Journal of Research in Interactive Marketing 7(2), 119-139. http://dx.doi.org/10.1108/JRIMMar-2012-0013

Boyes, J.A. \& Irani, Z., 2004, 'An analysis of the barriers and problems to web infrastructure development experienced by small businesses', International Journal of Information Technology and Management 3(2/4), 189-207. http:// dx.doi.org/10.1504/IJITM.2004.005032

Brunn, D.S. \& Dodge, M., 2001, 'Mapping the "worlds" of the World Wide Web: (Re) structuring global commerce through hyperlinks', American Behavior Scientists 44(10), 1717-1739. http://dx.doi.org/10.1177/0002764201044010011

Chen, C.-Y., Shih, B.-Y., Chen, Z.-S. \& Chen, T.-H., 2011, 'The exploration of internet marketing strategy by search engine optimization: A critical review and comparison', African Journal of Business Management 5(12), 4644-4649.

Craven, T.C., 2003, 'HTML tags as extraction cues for webpage description construction', Information Science Journal 6, 1-12.

Crowley, M., 2014, 'Take the guesswork out of your marketing strategy', Journal of Financial Planning 27(1), 16.

Green, D., 2000, 'The evolution of Web searching', Online Information Review 24(2), 124-137. http://dx.doi.org/10.1108/14684520010330283

Guenther, K., 2014, 'Getting your website recognized', Online Magazine, Issue May/ June, 47-49. Guidelines for optimising and making your site searchable, 2014, viewed 01 March 2015, from http://www.ananzi.co.za/submit/guidelines

Gupta, A. \& Mateen, A., 2014, 'Exploring the factors affecting sponsored search ad performance', Marketing Intelligence \& Planning 32(5), 586-599. http://dx.doi. org/10.1108/MIP-05-2013-0083

Henzinger, M.R., Motwani, R. \& Silverstein, C., 2002, 'Challenges in web search engines', viewed 30 April 2015, from http://www.acm.org/sigs/sigir/forum/ F2002/henzinger.pdf
Hubbard, J., 2004, 'Indexing the Internet', in Essay for Drexel University College of Information Science and Technology, viewed 25 April 2015, from http://www. tk421.net/essays/babel.html

Kennedy, K. \& Kennedy, B.B., 2008, 'A small company's dilemma: Using search engines effectively for corporate sales', Management Research News 31(10), 737-745. http://dx.doi.org/10.1108/01409170810908499

Kent, P., 2012, Search engine optimization for dummies, 5th edn., Wiley and Sons, Hoboken.

Kisiel, R., 2010, 'Dealers get on top of search engine results', Automotive News 84(6408), 24-25.

Kumar, E. \& Kohli, S., 2007, 'A strategic analysis of search engine advertising in web based-commerce', Journal of Internet Banking \& Commerce 12(2), 1-13.

Lee, W.I., 2010, 'The development of a qualitative dynamic attribute value mode for healthcare institutes', Iranian Journal of Public Health 39(4), 15-25. PMID: 23113034.

Lee, W.I., Chen, C.W. \& Wu, C.H., 2010, 'Relationship between quality of medical treatment and customer satisfaction - A case study in dental clinic association', International Journal of Innovative Computing, Information and Control 6 , 1805-1822.

Lee, W.I. \& Lin, C.H., 2011, 'Consumer hierarchical value map modeling in the healthcare service industry', African Journal of Business Management 5(3), 722-736.

Malaga, R.A., 2010, 'Search engine optimization - Black and white hat approaches', Advances in Computers 78, 1-39. http://dx.doi.org/10.1016/S0065-2458(10)78001-3

Mancuso, A., 2013, 'How Google AdWords' Ad Rank Algorithm Update Increased Brand CPC's by 600 Percent', viewed 12 May 2015, from http://www.seerinteractive. com/blog/how-google-adwords-ad-rank-algorithm-update-increased-brandcpcs-by-600

Moreno, L. \& Martinez, P., 2013, 'Overlapping factors in search engine optimization and web accessibility', Online Information Review 37(4), 564-580. http://dx.doi. org/10.1108/OIR-04-2012-0063

Moxley, D., Blake, J. \& Maze, S., 2004, 'Web search engine advertising practices and their effect on library service', The Bottom Line: Managing Library Finances 17(2), their effect on library service', The Bottom Line: Managing
$61-65$. http://dx.doi.org/10.1108/08880450410536080

Murphy, H.C. \& Kielgast, C.D., 2008, 'Do small and medium-sized hotels exploit search engine marketing?', International Journal of Contemporary Hospitality Management 20(1), 90-97. http://dx.doi.org/10.1108/09596110810848604

Nabout, N.A., 2015, 'A novel approach for bidding on keywords in newly set-up search advertising campaigns', European Journal of Marketing 49(5/6), 668-691. http:// dx.doi.org/10.1108/EJM-08-2013-0424

Nielsen, J., 2014, 'Top ten global web parent companies', viewed 08 March 2015, from http://www.nielsen.com/us/en/top10s.html

Olbrich, R. \& Schultz, C.D., 2014, 'Multichannel advertising: Does print advertising affect search engine advertising?', European Journal of Marketing 48(9/10), 1731 1756. http://dx.doi.org/10.1108/EJM-10-2012-0569

Onaifo, D. \& Rasmussen, D., 2013, 'Increasing libraries' content findability on the web with search engine optimization', Library Hi-Tech 31(1), 87-108. http://dx.doi. org/10.1108/07378831311303958

Oppenheim, C., Morris, A. \& McKnight, C., Lowley, S., 2000, 'The evaluation of WWW search engines', Journal of Documentation 56(2), 190-211. http://dx.doi. org/10.1108/00220410010803810

Plaza, B., 2009, 'Monitoring web traffic source effectiveness with Google Analytics: An experiment with time series', Aslib Proceedings 61(5), 474-482. http://dx.doi. org/10.1108/00012530910989625

Sagin, E., 2013, 'What the new AdWords ad rank algorithm really means', viewed 29 January 2015, from http://www.wordstream.com/blog/ws/2013/10/24/ adwords-ad-rank-algorithm

Sen, R., 2005, 'Optimal search engine marketing strategy', International Journal of Electronic Commerce 10(1), 9-25.

Singh, A.M., 2002, 'The Internet - Strategies for optimal utilization in South Africa', South African Journal of Information Management 4(1). http://dx.doi. org/10.4102/sajim.v4i1.152

Thelwall, M., 2001, 'Commercial web site links', Internet Research 11(2), 114-124. http://dx.doi.org/10.1108/10662240110388224

Vaughan, L., 2014, 'Discovering business information from search engine query data', Online Information Review 38(4), 562-574. http://dx.doi.org/10.1108/OIR-082013-0190

Visser, E.B. \& Weideman, M., 2011, 'An empirical study on website usability elements and how they affect search engine optimisation', South African Journal of Information Management 13(1). 9 pages. http://dx.doi.org/10.4102/sajim.v13i1.428

Weideman, M., 2013, 'Comparative analysis of homepage website visibility and academic rankings for UK universities', Information Research 18(4), viewed 30 April 2015, from http://InformationR.net/ir/18-4/paper599.html

Weideman, M., 2009, Website visibility: The theory and practice of improving ranking, Chandos Publishers, Oxford.

Zuze, H. \& Weideman, M., 2013, 'Keyword stuffing and the big three search engines', Online Information Review 37(2), 268-286. http://dx.doi.org/10.1108/OIR-112011-0193 